\title{
A INTERPRETAÇÃO DOS CONTRATOS DE PRESTAÇÃO DE SERVIÇOS DE SAÚDE À LUZ DO PRINCÍPIO DA DIGNIDADE DA PESSOA HUMANA*
}

\section{THE INTERPRETATIOM OF CONTRACTS TO PROVIDE HEALTH SERVICE WITH THE LIGTH OF THE PRINCIPLE OF DIGNITY OF HUMAN PERSON}

\author{
Agenor Domingos Lovato Cogo Júnior \\ Adauto de Almeida Tomaszewski"
}

\begin{abstract}
Resumo: A dignidade da pessoa humana, enquanto um dos princípios fundantes da República Federativa do Brasil e do Estado Democrático de Direito, deve, sempre que possível, ser levada em linha de conta quando da interpretação de um contrato de prestação de serviços de saúde pelo operador do Direito, diante de um caso concreto. Colocada essa premissa, tem o presente estudo como objetivo primordial, efetuar a análise das diversas regras de interpretação dos contratos de prestação de serviços de saúde à luz dos princípios e normas constitucionais, assim como da legislação infraconstitucional aplicável à espécie, visando o equilíbrio econômico e a busca da justiça contratual. O tema é relevante, pois o número de beneficiários de contratos de prestação de serviços de saúde aumenta a cada ano, diante da incapacidade do Estado em prover a todos os cidadãos o modelo sanitário insculpido no artigo 196 da Constituição Federal de 1988, conferindo à iniciativa privada a possibilidade de exploração dessa relevante atividade estatal (artigos 170 e 199 da CF/99). Por fim, procura estimular as partes envolvidas no contrato a efetuar um verdadeiro e permanente debate, fruto de uma reflexão crítica sobre todas as variáveis envolvidas no contexto, visando à melhoria de todo o sistema de saúde (público e privado), e, de consequência, o fiel cumprimento das diretrizes constitucionais, vez que o artigo XXV da Declaração Universal dos Direitos do Homem assegura a toda pessoa o direito a uma prestação sanitária ampla e digna.
\end{abstract}

Palavras-chave: Dignidade da pessoa humana. Contrato. Prestação de serviços de saúde. Interpretação constitucional.

Artigo extraído da Dissertação de Mestrado, apresentada ao Programa de PósGraduação Strictu Sensu da Universidade Estadual de Londrina/PR, de autoria do primeiro, sob a orientação do segundo.

* Mestre em Direito Negocial, na área de concentração de Direito Civil. Advogado Conselheiro da OAB Londrina/PR. Coordenador do Núcleo de Prática Jurídica do Curso de Direito da Unopar Londrina/PR. E-mail: agenorcogojr@uol.com.br.

***Mestre em Direito Negocial pela Universidade Estadual de Londrina/PR. Doutor em Direito pela PUC/SP. Professor dos cursos de Graduação e Especialização em Direito da PUC/PR - Campus Londrina/PR. Professor do Curso de Mestrado em Direito Processual e Cidadania da UNIPAR - Campus de Umuarama/PR. Autor de diversas obras e artigos jurídicos. E-mail: adauto@uel.br. 


\begin{abstract}
The dignity of the human person, as one of the founding principles of the Federative Republic of Brazil and the Democratic State must, even as possible, be respected when interpreting a contract of health service providing by the operator of right in front of a concrete case. After showing this premise, this study has as main objective to perform an analysis of the many rules of interpretation of the contracts of health service providing, in face of the principles and constitutional norms, as well as infra-constitutional legislation applicable to it, also aiming to acquire economic equilibrium and contractual justice. This theme is very relevant, because the number of beneficiaries of contracts of health service increases every year, before State's inability to provide to all citizens a public health model, sculptured in article 196 of the Constitution of 1988 , giving to the private business the possibility of exploration of this relevant state activity (articles 170 and 199 of the Constitution of 1988). Finally, it aims to encourage the parties involved in the contract to have a real and permanent debate, as a result of a critical reflection about all the variables involved in this context, aimed also to improve the entire health system (public and private ones), and, as a consequence of it, the faithful fulfillment of constitutional guidelines, because the article XXV of the Universal Declaration of Human Rights guarantees to every person the right to have a comprehensive health and dignity.
\end{abstract}

Key-words: Human dignity. Contract. Health service providing. Constitutional interpretation.

\title{
INTRODUÇÃO
}

O presente artigo tem por objetivo analisar as formas de interpretação dos contratos de prestação de serviços de saúde previstos na legislação específica, sob a ótica do princípio da dignidade da pessoa humana, vez que a Constituição da República Federativa do Brasil elenca a saúde, dentre outros direitos sociais, como um direito de natureza fundamental de todos os cidadãos brasileiros e, portanto, um dever do Estado.

Tem ainda por desiderato, mediante o cotejo dessa realidade com a faculdade conferida pelo legislador Constituinte de permitir a exploração dessa atividade fundamental (saúde) pela iniciativa privada, conferida pelos artigos 170 e 199 da Constituição Federal, buscar fornecer aos operadores do Direito, diante de um caso concreto, subsídios para uma correta interpretação de referidos contratos, visando a busca da justiça contratual, basilar fundamento da intervenção estatal.

Trata também de abordar questões de ordem hermenêutica ao discorrer sobre a interpretação dos contratos em geral e dos contratos de adesão, dadas as suas particularidades, focando, contudo, a análise sob a ótica do princípio da dignidade de pessoa humana, força motriz e inspiradora do presente estudo, por meio da análise da interpretação dos contratos de prestação de serviços 
de saúde à luz do princípio da dignidade da pessoa humana, da explicação da origem histórica do termo e da importância de referido primado, enquanto elemento fundante da República e do Estado Democrático de Direito.

\section{A INTERPRETAÇÃO DOS CONTRATOS DE PRESTAÇÃO DE SERVIÇOS DE SAÚDE E O PRINCÍPIO DA DIGNIDADE DA PESSSOA HUMANA}

\subsection{A Origem do Termo "Dignidade da Pessoa Humana"}

O vocábulo latino persona, para alguns, inicialmente designava a máscara usada pelos atores em apresentações teatrais, não uma pessoa, mas um papel (LUDWIG, 2002, p. 265). Para outros, como Cretella Júnior, persona, deriva do etrusco "phersu" (não do latim persona) e significava o homem capaz de direitos e obrigações (CRETELLA JÚNIOR, 2001. p. 53). Contudo, para os romanos, homem e pessoa eram conceitos diversos, sendo o primeiro biológico e o segundo jurídico. A pessoa era o ser humano acompanhado de certos atributos, requisitos.

Igualmente, a civilização romana contemplava a existência de seres humanos que não eram considerados pessoas, mas res, coisas (os escravos).

Já em relação à raiz etimológica da palavra dignidade, esta provém do latim dignus, ou seja, "aquele que merece estima e honra, aquele que é importante" (MORAES, 2000, p. 112). Na linguagem comum, a palavra dignitas foi empregada primeiramente no sentido de função, cargo, título, vinculada à posição ocupada na sociedade, segundo a estudiosa sobre o tema, Béatrice Maurer (2005, p. 64.)

E qual a razão de todos os seres humanos serem considerados sujeitos de direitos e igualmente dignos? A resposta estava no fato de o Cristianismo considerar ter sido o homem concebido à imagem e semelhança de Deus. Se todos os homens foram concebidos à imagem e semelhança de Deus, todos seriam iguais, merecendo respeito independentemente da titulação, das posses e das qualidades. Este pensamento enriqueceu a palavra "pessoa" que deixou de ser status para tornar-se atributo natural do ser humano. Nesse sentido antropológico-cristão, destaca-se a filosofia medieval, como a de Tomás de Aquino.

Em época mais recente, após o processo de laicização (secularização) e racionalização do direito, destacaram-se de modo significativo os conceitos de pessoa de Hobbes, Locke, Descartes e, em especial, Kant. O pensamento deste último influenciou o pensamento ocidental sobre o significado e o conteúdo da dignidade.

Para Kant, de maneira muito sucinta, o ser humano existe como um fim em si mesmo, não como meio para exercício arbitrário de satisfação desta 
ou daquela vontade. O ser humano, como único valor absoluto, deve ser considerado sempre como fim, jamais pode ser tratado como objeto. É um dever negativo de não se impor sobre o outro (MORAES, 2000, p. 115)

A construção teórica de Kant passou a influenciar profundamente a doutrina e a produção jurídica. Essa construção (apesar das críticas de ser uma visão liberal) prevalece no pensamento filosófico e jurídico atual: o ser humano como fim e não como meio.

Realmente, os ensinamentos de Kant merecem destaque, mas a concepção de dignidade continuou a evoluir e a ganhar outras perspectivas.

O marco histórico para o assunto - dignidade da pessoa humana - foi a Segunda Guerra Mundial e as violações cometidas. A partir deste marco, o assunto passou a ser destaque no campo científico e filosófico e foi necessária a constitucionalização do princípio da dignidade da pessoa humana, inicialmente na Alemanha e, posteriormente, em diversas outras constituições (MARTINS, 2006, p. 32-3).

Portanto, com o final da Segunda Guerra, passou-se a uma perspectiva axiológica e humanista do Direito, baseada na dignidade da pessoa humana (LUDWIG, 2002, p. 285).

Importante ressaltar que, o termo dignidade passou por diferentes concepções na história: primeiro uma concepção individualista (prevalência do indivíduo), depois transpersonalista (prevalência do interesse coletivo sobre o individual) e enfim, personalista. Esta última é adotada na atualidade, diferenciando-se indivíduo e pessoa: o primeiro como ente abstrato e o segundo como ente concreto, real. Para esta última corrente, há de compatibilizar os valores individuais com o coletivo. Havendo conflito, a solução deverá ser buscada caso a caso (SANTOS, 1998, p. 27).

Das premissas acima, infere-se que tanto a palavra pessoa, como a palavra dignidade, apresentou diferentes conotações no desenrolar da história. É possível constatar que sempre existiu uma proteção do ser humano desde as legislações mais antigas, mas esta proteção não era estendida a todos, pois nem todos eram iguais, livres e sujeitos de direitos e deveres. A dignidade da pessoa humana enquanto valor, estendida a todos, representa uma conquista da humanidade, embora o assunto, não se encontre pronto e acabado. $O$ tema reveste-se sempre de atualidade, sob uma visão personalista, comportando debates na busca de uma maior proteção jurídica.

Todavia, o que importa para o presente momento é que o princípio da dignidade da pessoa humana constitui-se, com o advento da Constituição Federal de 1988, como um dos fundamentos da República Federativa do Brasil e do Estado Democrático de Direito, consoante será adiante explicitado. 


\subsection{O Princípio da Dignidade da Pessoa Humana como Fundamento da República}

Analisando-se a Constituição Federal Brasileira, em seu Título I, verifica-se, de plano, os Princípios Fundamentais da República. Neste momento, referido Diploma estabelece que a República Federativa do Brasil é formada pela união indissolúvel dos Estados, Municípios e do Distrito Federal, constituindo-se em um Estado Democrático de Direito que tem, como fundamentos, cinco princípios básicos: a soberania, a cidadania, a dignidade da pessoa humana, os valores sociais do trabalho e da livre iniciativa e o pluralismo político (destaque de agora).

Tais princípios constitucionais, enquanto guardiões dos valores fundamentais da ordem jurídica embasam os Direitos Fundamentais do indivíduo trazidos pelo Título II da Magna Carta, consagrando-os como referência do ordenamento jurídico, não se podendo olvidar, contudo, que não há grau de hierarquia entre eles (direitos fundamentais), devendo, pois, ser analisados como direitos interdependentes, e assim acumulados, consoante leciona Alexandre de Moraes ao sustentar que:

O conjunto institucionalizado de direitos e garantias do ser humano que tem por finalidade básica o respeito a sua dignidade, por meio de sua proteção contra o arbítrio do poder estatal e o estabelecimento de condições mínimas de vida e desenvolvimento da personalidade humana [...] (MORAES, 2000, p. 39).

Dentre os princípios fundamentais citados acima, destaca-se o da dignidade da pessoa humana, que possui característica e conceituação ampla, vez que tutela a vida do indivíduo em sociedade, especialmente no que tange às garantias que lhes são asseguradas constitucionalmente.

É a dignidade da pessoa humana, dentro da Constituição da República, assim como os demais direitos fundamentais, valor supremo. De sua análise se extrai que, no momento estatal vigente após 1988, vem ser o homem o personagem principal da ordem jurídica. Assim, no dizer de Flademir Jerônimo Belinati Martins, a pessoa humana passa a ser concebida como centro do universo jurídico e prioridade justificante do Direito (MARTINS, 2006, p. 72).

Ademais, deriva da dignidade a que faz jus todo aquele que se ampara sob o teto do Estado Democrático de Direito, garantindo-lhe a integridade dos Direitos e garantias fundamentais.

Para Luis Roberto Barroso, o princípio da dignidade da pessoa humana identifica um espaço de integridade moral a ser assegurado a todas as pessoas pelo simples fato de existirem. 
Nesse sentir, leciona o citado autor que:

A dignidade relaciona-se tanto com a liberdade e valores do espírito como com as condições materiais de subsistência. O desrespeito a este princípio terá sido um dos estigmas do século que se encerrou e a luta por sua afirmação um símbolo do novo tempo. Ele representa a superação da intolerância, da discriminação, da exclusão social, da violência, da incapacidade de aceitar o outro, o diferente, na plenitude de sua liberdade de ser, pensar e criar (BARROSO, 2003, p. 51-2).

Consiste, assim, a dignidade da pessoa humana, na prerrogativa assistida a todo ser humano, de ser respeitado como pessoa, de ter acesso a uma existência digna, e de ver garantida uma vivência material mínima.

Diante disso é que, a dignidade da pessoa humana foi introduzida no ordenamento jurídico brasileiro como um princípio de observação obrigatória, de natureza superior, além de legitimador de toda e qualquer atuação estatal e privada. É, como visto, valor fonte de todo o sistema jurídico-social e fundamento do Estado Democrático de Direito.

Para Ingo Wolfgang Sarlet, a dignidade da pessoa humana consiste na:

[...] qualidade intrínseca e distintiva reconhecida em cada ser humano, que o faz merecedor do mesmo respeito e consideração por parte do Estado e da comunidade, implicando, neste sentido, um complexo de direitos e deveres fundamentais que assegurem a pessoa tanto contra todo e qualquer ato de cunho degradante e desumano, como venham a lhe garantir as condições existenciais mínimas para uma vida saudável, além de propiciar e promover sua participação ativa e co-responsável nos destinos da própria existência e da vida em comunhão com os demais seres humanos (SARLET, 2007, p. 62). A situação de referido princípio em um nível axiológico-normativo superior é que determina seu reconhecimento como valor fonte do sistema constitucional, a si vinculando toda atuação legislativa e judicial, sob pena de ir contra o intuito do legislador Constituinte e, via de regra, contra os fundamentos da República.

Neste sentido Flávia Piovesan leciona que:

[...] o valor da dignidade da pessoa humana impõe-se como núcleo básico e informador de todo ordenamento jurídico, como critério e parâmetro de valoração a orientar a interpretação e compreensão do sistema constitucional. Pode-se afirmar, considerando que toda Constituição há de ser compreendida como uma unidade e como um sistema que privilegia determinados valores sociais, que a Carta de 1988 elege o valor da dignidade da pessoa humana como um valor essencial que the doa unidade de sentido [...] (PIOVESAN, 2006, p. 227). 
Dentre os valores sociais louvados pelo sistema constitucional brasileiro e abrangidos pelo princípio da dignidade da pessoa humana, está o direito fundamental à vida, disposto na Constituição Federal no caput do artigo $5^{\circ}$.

Enquanto um direito fundamental, o direito à vida consiste em um desdobramento do princípio da dignidade da pessoa humana. Isto posto, não é possível falar em garantia do direito à vida sem se ver assegurada a dignidade do indivíduo, enquanto preceito fundamental.

Ainda para Ingo Sarlet, não é possível dissociar a dignidade da pessoa humana dos direitos fundamentais. Veja-se:

Com efeito, sendo correta a premissa de que os direitos fundamentais constituem [...] explicitações da dignidade da pessoa, por via de conseqüência e, ao menos em princípio [...], em cada direito fundamental se faz presente um conteúdo ou, pelo menos, alguma projeção da dignidade da pessoa (SARLET, 2007, p. 86).

Sendo assim, qualquer atuação que fira o direito à vida terá como efeito o desrespeito à dignidade da pessoa humana, vez que existe íntima ligação entre eles.

Ademais, situa-se o direito à vida, dentro da gama de direitos fundamentais assegurados aos indivíduos, como uma categoria, sem a qual não se exerce nenhum outro direito. Desta forma, não há que se falar em direito à igualdade, à segurança e à propriedade, à saúde, sem que se veja assegurado plenamente o direito à vida.

Neste sentido, Alexandre de Moraes afirma que:

A Constituição Federal garante que todos são iguais perante a lei, sem distinção de qualquer natureza, garantindo-se aos brasileiros e aos estrangeiros residentes no País a inviolabilidade do direito à vida, à liberdade, à igualdade, à segurança e à propriedade. $\mathrm{O}$ direito à vida é o mais fundamental de todos os direitos, já que se constitui pré-requisito à existência e exercício de todos os demais direitos. A Constituição Federal proclama, portanto, o direito à vida, cabendo ao Estado assegurá-lo em sua dupla acepção, sendo a primeira relacionada ao direito de continuar vivo e a segunda de se ter vida digna quanto à sua subsistência (MORAES, 2000, p. 61-2).

A função do Estado, ao assegurar referidos direitos, é promover e garantir aos indivíduos melhores condições de vida em sociedade. Isto pois, materializase e se assegura o direito à vida por meio da atuação estatal, seja por meio de medidas de segurança pública, seja por meio de políticas de saúde.

Diante disso é que, ao falar do direito à vida, é impossível não associá-lo ao direito à saúde, enquanto direito fundamental social inerente a cada indivíduo, 
e como consequência direta do princípio da dignidade da pessoa humana. Partindo destas premissas é que a interpretação dos contratos de serviços de prestação de serviços de saúde deve ser efetivada quando ocorrer um conflito entre os interesses antagônicos das partes contratantes, buscando sempre uma verdadeira justiça e equilíbrio contratuais.

\subsection{A Interpretação dos Contratos em Geral}

O primeiro aspecto que se deve ter em mente ao analisar um contrato é que ele é uma categoria de negócio jurídico e, como tal, tem as suas teorias interpretativas baseadas nos princípios que balizam a interpretação deste último. A exegese de ambas as modalidades tem como objetivo o de fixar o sentido de uma manifestação da vontade.

A moderna teoria jurídica também aproxima o contrato da lei, pois são geradores de efeitos análogos, porém distintos em sua extensão (PEREIRA, 2004, v. 3, p. 50).

Em virtude disso, os contratos também herdam os mesmos princípios de hermenêutica das leis.

A manifestação da vontade tem dois elementos distintos: o interno (a vontade real) e o externo (a declaração propriamente dita). E, a partir desses dois elementos, elaboram-se duas teorias interpretativas que levam as distinções apresentadas ao extremo: a teoria da vontade, que leva em consideração apenas a vontade real das partes, a intenção, independentemente daquilo que é declarado no contrato, sendo esta posição defendida por Savigny, e a teoria da declaração, na qual somente a exteriorização da vontade deve prevalecer, ou seja, a declaração tem proeminência sobre a vontade em si.

Frente a essas duas posições extremadas, o Direito brasileiro adotou uma postura mais central, quando alega, no artigo 112 do Código Civil, que "nas declarações de vontade se atenderá mais à intenção nelas consubstanciada do que ao sentido literal da linguagem.” Desta forma, segundo leciona Venosa "o intérprete não pode simplesmente abandonar a declaração da vontade e partir livremente para investigar a vontade interna” (VENOSA, 2003a, v.1, p. 419).

Além do artigo 112 já mencionado, o Código Civil também traz outros dispositivos que orientam o operador do direito na interpretação dos contratos. É importante observar que tais normas são somente orientações ao exegeta, visto que eles foram fruto das discussões doutrinárias e jurisprudenciais já sedimentadas na prática forense, tratando-se apenas de lembretes ao magistrado.

São eles o artigo 110, que trata sobre a reserva mental, alegando que a cláusula estipulada é válida se o contraente desconhecia artifício utilizado pela outra 
parte; o artigo 111, que trata do silêncio circunstanciado e declara a anuência ao estipulado quando as circunstâncias ou os usos assim o autorizarem; o artigo 114, que aconselha que os negócios jurídicos benéficos e a renúncia sejam interpretados de maneira estrita; e os artigos 421 e 422 (juntamente com o artigo 113), que emergem como os novos paradigmas do direito contratual, quais sejam, a função social do contrato e o princípio da boa-fé objetiva, já analisados no item 3.3 retro, de suma importância, mormente para a interpretação dos contratos de adesão, grande característica dos contratos objetos do presente estudo.

Não obstante essas regras positivadas, a doutrina ainda aponta para outras, dentre as quais podemos destacar os ensinamentos de Mônica Yoshizato:

[...] a melhor maneira de se apurar a intenção dos contratantes é verificar o modo pela qual vinham executando o contrato, de comum acordo; o contrato deve ser interpretado de maneira menos gravosa para o devedor, quando for contrato gratuito, ou tendente ao equilíbrio, quando oneroso; se existir cláusula que importe dois significados deve-se utilizar aquele que torne o contrato exequível; o contrato é um todo e, como tal, suas cláusulas devem ser interpretadas em conjunto, de maneira sistemática; interpreta-se em prejuízo daquele que deveria ser claro, mas não foi; e, semelhante ao contrato de adesão, quando houver dúvida, a cláusula deve ser interpretada em favor daquele que contraiu a obrigação em detrimento daquele que estipulou o contrato [...] (BIERWAGEN, 2003, p. 92).

Percebe-se, pois, a importância do tema que encontra soluções para a resolução dos conflitos apresentados nos casos em concreto tanto na doutrina, como visto acima, assim como na vasta jurisprudência, consoante será exposto em capítulo próprio, onde se apresentará suporte jurisprudencial de casos e notícias relacionados ao tema objeto do presente estudo, levados a efeito ao longo de dois anos de pesquisa, com o objetivo de auxiliar e nortear os operadores do Direito nesta árdua missão.

\subsection{A Interpretação dos Contratos de Adesão}

A estrutura ímpar dos contratos de adesão, dentre os quais se inclui a grande maioria dos contratos de prestação de serviços de saúde, não permite que eles sejam interpretados da mesma maneira que os demais contratos, principalmente em virtude da mitigada autonomia da vontade, característica marcante neste tipo de técnica contratual, observada no predomínio da vontade de um dos contratantes.

O Código Civil vigente trouxe apenas dois artigos específicos sobre as regras 
de interpretação dos contratos de adesão: o artigo 423 e o 424. Somam-se a esses as demais regras formuladas pela doutrina e seguidas pelos tribunais, além da obrigatória observação dos princípios contratuais, dentre os quais se destacada o da boa-fé objetiva, o mais importante em se tratando de contratos de adesão.

O artigo 423 relata que "quando houver no contrato de adesão cláusulas ambíguas ou contraditórias, dever-se-á adotar a interpretação mais favorável ao aderente." Cláusulas ambíguas são aquelas que oferecem mais de um sentido, a partir da interpretação gramatical. Já as contraditórias são aquelas em que o conteúdo de uma delas é incompatível com o disposto em outra cláusula.

Referido artigo é a regra fundamental dos contratos de adesão, e advém do Direito romano: interpretatio contra stipulatorem. Tem justificativa a sua aplicação no Direito atual em virtude da impossibilidade da discussão prévia das cláusulas do contrato as quais já estão previamente redigidas e estipuladas, sem possibilidade da parte contratante (aderente) discutir livremente as suas cláusulas e as obrigações delas decorrentes.

Estabelece-se, com isso, uma vantagem ao aderente, parte mais vulnerável, amenizando desta forma o desequilíbrio da relação contratual.

O dispositivo em comento tem dupla função: ao mesmo tempo em que inibe o predisponente na elaboração de cláusulas abusivas ou que ensejem excessiva vantagem para si (natureza preventiva), determina a leitura mais favorável ao aderente, quando presentes tais aberrações (natureza corretiva).

Já o artigo 424, estabelece que "nos contratos de adesão, são nulas as cláusulas que estipulem a renúncia antecipada do aderente a direito resultante da natureza do negócio.”

Nos dizeres de Bierwagen (2003, p. 96):

Quis o legislador proteger os direitos correlatos que na prática comercial são comumente excluídas por cláusulas padrão como a de não-reparação pelos danos decorrentes de defeitos da coisa ou pela má prestação de serviços, nãoindenizabilidade de vícios redibitórios, evicção, etc.

Como se tratam de cláusulas nulas, estas podem ser alegadas a qualquer tempo e serem decretadas de ofício pelo juiz, além de terem seus efeitos retroagidos no tempo (eficácia ex nunc).

A doutrina também traz outras regras, cujo escopo é a busca do equilíbrio contratual, que também deve ser observado nos contratos de adesão, característica marcante dos contratos de prestação de serviços de saúde. As principais são: as cláusulas dúbias e obscuras devem ser interpretadas em favor do aderente, da mesma forma que acontece com as cláusulas ambíguas e controversas; as 
cláusulas agregadas, ou seja, aquelas manuscritas ou datilografadas, quando incompatíveis com as condições gerais do contrato, devem prevalecer, pois se presume que elas foram discutidas previamente; quando o contrato de adesão for nominado, as normas dispositivas prevalecem sobre as condições gerais se houver choque entre elas; e, as condições gerais do contrato devem estar de acordo com o princípio da boa-fé objetiva (LÔBO NETTO, 1991, p. 134-7).

O Código de Defesa do Consumidor, por seu turno, possui muitas regras de interpretação dos contratos consumeristas, mas somente o artigo 54 regula os contratos de adesão.

É importante frisar nesse passo, que a interpretação presente em referido Codex não só incidirá sobre o vínculo contratual entre consumidor e fornecedor, assim definidos nos artigos $2^{\circ}$ e $3^{\circ}$ da Lei $n^{\circ} 8078 / 90$.

Determinam, em síntese, os parágrafos do artigo 54 que: a mera inserção de cláusula no formulário não descaracteriza o contrato de adesão; só poderá existir cláusula resolutória se ela for alternativa e se a escolha entre a resolução e a manutenção do contrato for do consumidor (aderente); os contratos devem ser escritos com caracteres ostensivos e legíveis, eliminando as chamadas "letras miúdas"; e as cláusulas limitativas de direitos devem ser destacadas, de modo a facilitar a compreensão por parte do aderente.

Art. 54 - Contrato de adesão é aquele cujas cláusulas tenham sido aprovadas pela autoridade competente ou estabelecidas unilateralmente pelo fornecedor de produtos ou serviços, sem que o consumidor possa discutir ou modificar substancialmente seu conteúdo.

$\S 1^{\circ}$ - A inserção de cláusula no formulário não desfigura a natureza de adesão do contrato.

$\S 2^{\circ}$ - Nos contratos de adesão admite-se cláusula resolutória, desde que alternativa, cabendo a escolha ao consumidor, ressalvando-se o disposto no $\S 2^{\circ}$ do artigo anterior.

$\S 3^{\circ}$ Os contratos de adesão escritos serão redigidos em termos claros e com caracteres ostensivos e legíveis, cujo tamanho da fonte não será inferior ao corpo doze, de modo a facilitar sua compreensão pelo consumidor. (Alterado pela Lei$11785 / 2008)$

$\S 4^{\circ}$ - As cláusulas que implicarem limitação de direito do consumidor deverão ser redigidas com destaque, permitindo sua imediata e fácil compreensão.

Como visto, dadas as peculiaridades dos contratos de adesão, dentre os quais se inclui a grande maioria dos contratos de prestação de serviços de saúde, devem os mesmos ser interpretados de maneira diferenciada em relação aos demais tipos de contratos, principalmente em razão do predomínio da vontade 
de um dos contratantes sobre a do outro sem a possibilidade de discussão prévia das cláusulas contratuais.

Vale ressaltar, além disso, que deve o operador do Direito interpretar o contrato de prestação de serviços de saúde à luz da Constituição Federal e dos princípios constitucionais atinentes à espécie, especialmente o da dignidade da pessoa humana, sobre o qual se assenta e fundamenta a presente dissertação, pois assim procedendo estará contribuindo para a consolidação dos princípios fundantes da República Federativa do Brasil e do Estado Democrático de Direito, constantes do preâmbulo da Constituição Federal de 1988.

\subsection{A Interpretação dos Contratos de Prestação de Serviços de Saúde à Luz do Princípio da Dignidade da Pessoa Humana}

De tudo que foi visto até o presente momento, importante destacar e realçar que os contratos objeto do presente estudo, devem ser interpretados sob a ótica do princípio da dignidade da pessoa humana, força motriz e inspiradora deste artigo, ressaltando, contudo que os resultados e conclusões ora apresentadas não se tratam de respostas finais, acabadas, mas apenas de novas perspectivas de exegese dos contratos em epígrafe, a sugerir e permitir novas atribuições de significado no Direito e na Saúde, visando a busca de uma verdadeira justiça contratual pelos operadores do Direito, diante de um caso concreto.

Nesse sentido, as ilações deduzidas ao longo deste trabalho, permitem asseverar, com certa margem de segurança, que o panorama que se apresenta para o setor é promissor, senão vejamos.

As cores da constitucionalização, repersonalização e descodificação do Direito Civil (re)definem o cenário. Seus princípios e regras compõem as matizes que colorem o panorama jurídico dos contratos de prestação de serviços de saúde, a demandar a redefinição de seus contornos.

Sob estes novos ares, as normas e princípios constitucionais, dentre os quais se destaca o da dignidade da pessoa humana, estabelecem condutas, valores e fundamentos e, igualmente, operam como limites interpretativos, sendo que a antiga regra da "lex superior derogat inferior" é mitigada pela leitura axiológiconormativa, a qual atribui às leis novo valor.

Importante conjunto de transformações informa as perspectivas do Direito Civil brasileiro contemporâneo, especialmente no que pertine às figuras contratuais, dentre as quais se destaca aquelas relacionadas aos contratos de prestação de serviços de saúde, dada sua importância e repercussão social. Prima-se pela ideia de travessia (superação), em detrimento da noção de crise, assinalando o abandono do sentido estático dos institutos, trazendo a 
descoberta e a renovação, com a introdução das cláusulas gerais e conceitos legais indeterminados, que possibilitam a mobilidade e evolução do ordenamento jurídico.

A partir de uma leitura crítica, substituí-se o dogma pelo debate, promovendo $a$ abertura às novas possibilidades. A atribuição de feição dinâmica não significa condenar o passado, mas revê-lo com o escopo de fomentar a reconstrução.

Nem a tradição respalda a permanência nem a novidade justifica a substituição. Ao invés dos binários em oposições, os binômios compostos na relação: interpretação-aplicação, forma-conteúdo, público-privado, passadopresente. Nas pluralidades colhe-se a complexidade do real. Como símbolo da confluência de racionalidades, imperioso o "diálogo das fontes". O ordenamento, plural em seus valores, encontra sua integridade na unidade constitucional, de maneira que seu fio condutor assenta-se na tutela da pessoa e na proteção à sua dignidade em sua amplitude.

Na seara dos contratos de prestação de serviços de saúde, essa tutela é essencial e corresponde à indispensável exigência de medidas concretas aptas a sua efetivação. À luz de tais premissas e sob as lentes da contratualidade contemporânea, é que se procurou empreender um estudo acerca das modalidades de interpretação dos contratos de prestação de serviços de saúde, destacandose o respeito ao princípio da dignidade da pessoa humana, enquanto um dos elementos fundantes da República Federativa do Brasil.

Sem a ficção da ausência de ideologia, sublinha-se que o contrato, entre a cobertura jurídica e a essência econômica, é representativo de importantes conflitos de valores. Sua compreensão exige, desta sorte, apreender o seu arredor e localizá-lo no tempo e no espaço. Nessa toada, afirma-se a importância de meditar sobre a mercantilização da prestação da assistência médica, sendo imperativo levar em conta um ambiente em que os cuidados do corpo são objeto de negócio.

Entre as transformações na espacialidade, recebe destaque a construção de uma ponte entre o público e o privado. Tais esferas são tomadas como espaços distintos mais interligados, em perspectiva que alarga os horizontes interpretativos.

Na seara do Direito Civil, caminhar por essa ponte possibilita superar o isolamento do homem singular da Modernidade, afastar-se dos lugares comuns e descobrir, logo ali, antinomias, lacunas e situações antes desconsideradas.

No campo da saúde, em sentido diverso, todavia não divergente, o "mix público privado" acena para a insuficiência da dicotomia, evidencia a imbricação entre a prestação pública e privada, esmaece o sentido de oposição e confirma a necessidade do convívio de interesses individuais e coletivos. 
Pela via da eficácia direta ou da eficácia indireta, vale realçar, com ou sem intermediação pela lei, a incidência do direito à saúde deve ser imediatamente eficaz na tutela desses direitos. Nesse compasso, a reverberação do direito fundamental conduz a reflexões e problematizações, as quais repercutem significativamente no regime dos contratos de prestação de serviços de saúde. Destarte, deve-se buscar identificar a recorrente presença da ideia de "equilíbrio econômico" nas controvérsias judiciais acerca dos contratos de prestação de serviços de saúde, não se olvidando nunca, contudo, dos princípios e garantias constitucionais relacionados ao tema.

Estabelecer seu significado é, todavia, tarefa falsamente simples, devendose tomar em conta os vetores do tempo e da natureza do contrato. Para a operadora há tendência ao progressivo aumento dos investimentos a serem efetuados, com a ampliação das coberturas e procedimentos determinados pela ANS. Diversamente, para o contratante, o momento inicial é de acentuado desnível entre o valor das mensalidades pagas ao plano de saúde e sua utilização. Nessa esteira, deve haver um equilíbrio dinâmico de sorte que a equivalência das prestações não se confunda com seu peso idêntico a todo tempo.

Em face dessa ordem de ideias, infere-se que será, via de regra, insuficiente ou mesmo imprópria a análise do equilíbrio contratual que focalize um período de tempo restrito. Não se concebe que o beneficiário de um contrato de prestação de serviços de saúde peça restituição após breve tempo ser ter usufruído do contrato. De maneira semelhante, não se admite a resilição, pela operadora, de contrato de um cliente que se torna "caro demais". Haja vista que se trata de modalidade contratual de larga duração e acentuada catividade, o rompimento unilateral contrapõe sua natureza e ofende o equilíbrio.

A eficácia interprivada do direito fundamental à saúde atribui acentuada relevância à problematização da ideia de custo-benefício. Sua incidência mitiga o sentido de oposição e confere à expressão sentido dialético ao estabelecer sua ligação com a tutela da pessoa, de sua dignidade e sua saúde. Assim, traz a tona o indispensável liame entre Direito a Medicina e porque não dizer, a Economia, quando nos empresta os ensinamentos do princípio da reserva do possível, construção da doutrina alemã que regula a possibilidade e a extensão da atuação estatal no tocante à efetivação de alguns direitos (como, por exemplo, dos direitos sociais, dentre os quais se inclui o direito à saúde), condicionando a prestação do Estado à existência de recursos públicos disponíveis.

Nessa quadratura, a ausência de possibilidades de recuperação não justifica que, exclusivamente sob o prisma dos custos, se determine a suspensão de cuidados. Igualmente, inviável a limitação do tempo de internação ou a oferta 
um procedimento médico arriscado quando houver outro disponível em custo adequado.

Essa expressão, a qual certamente não oferece respostas, fomenta a discussão acerca do significado de custo-benefício na seara dos contratos de prestação de serviços de saúde. A relevância social destes pactos e os vários casos de insucesso de operadoras justificam atenção as suas finanças. Por essa razão, mister se faz um rígido controle nas prestações de contas, com fulcro na necessária transparência. Compreende-se que tal possibilidade independe da forma jurídica adotada pela operadora, de sua vocação beneficente ou voltada ao lucro, eis que a incidência do direito fundamental imprime a nota da essencialidade à atividade privada (lucrativa ou não), exigindo a proteção da coletividade e a observância dos princípios constitucionais inerentes, especialmente o da dignidade da pessoa humana.

Para arrematar, imperativo ressaltar, no binômio custo-benefício, o sentido muito especial que o segundo vocábulo atinge por força da tutela do direito fundamental à saúde e da dignidade da pessoa humana. Da dicotomia entre público e privado, caminha-se para a dialética entre a liberdade de ter e de ser. Assim, não pode passar despercebido que a própria designação do tema como eficácia dos direitos fundamentais nas relações interprivadas sugere uma tensão valorativa. $\mathrm{Na}$ perspectiva do contrato, e mais especificamente do contrato de prestação dos serviços de saúde, aflora o percurso do "laissez-faire" ao "is it fair", o qual não consiste em suprimir a liberdade, mas em buscar seu sentido contemporâneo, sem preconizar uma absolutização do Estado ou de um interesse geral, nem a condição absoluta à liberdade dos particulares.

Portanto, a reverberação do direito fundamental na seara das relações contratuais, ao promover a necessária interlocução entre Saúde, Direito e Economia (nessa ordem), ressoa de maneira direta no denominado "diálogo das fontes”, rompendo com a postura formal-indiferente, sintomática do modelo contratual clássico. Na composição dos planos contratual e da saúde, abrese o caminho para leitura axiológico-normativa representativa da dialética de valores da Contemporaneidade, apta a ensejar importantes problematizações vocacionadas à tutela da pessoa, de sua dignidade, de sua saúde e de sua vida.

Assim, tem o presente estudo como objetivo principal, mediante o cotejo de realidades tão extremadas, fornecer aos operadores do Direito, diante de um caso concreto, subsídios para uma correta interpretação de referidos contratos à luz dos primados constitucionais, dentre os quais se destacada o da dignidade da pessoa humana, visando a busca da justiça contratual, basilar fundamento da intervenção estatal. 
Todavia, importante destacar que a proposta do presente estudo visa apenas instigar e proporcionar uma ampla reflexão crítica sobre o assunto proposto, através de um verdadeiro debate entre as partes contratantes, que deverá ser mediado por meio de uma nova e eficaz perspectiva regulatória, com mudança no papel dos atores da saúde suplementar, onde operadoras se tornem gestoras de saúde; os prestadores de serviços, produtores de cuidado; os beneficiários, usuários com consciência sanitária e a Agência cada vez mais qualificada para regular o setor, o que resultará numa melhoria de todo o sistema, podendo assim, definitivamente, conferir à saúde efetivamente o status de bem público, erigido à condição de direito fundamental por nossa Carta Magna.

\section{CONCLUSÃO}

O presente estudo buscou efetuar uma análise das diversas modalidades de interpretação dos contratos de prestação de serviços de saúde existentes no Brasil, visando fornecer parâmetros razoáveis e seguros de interpretação desses contratos, à luz dos princípios e normas civilistas, consumeristas e constitucionais, dentre os quais se pretendeu dar maior relevo ao princípio da dignidade da pessoa humana, enquanto um dos elementos fundantes da República Federativa do Brasil e do Estado Democrático de Direito, visando o equilíbrio econômico e a busca da justiça contratual.

Aliás, sobre o princípio da dignidade da pessoa humana, inserido no inciso III, do artigo $1^{\circ}$ da Constituição Federal, e que foi o "fio condutor" do presente estudo, buscou-se destacar que referido princípio promove uma despatrimonialização e uma repersonalização do direito civil, com ênfase em valores existenciais e do espírito, bem como no reconhecimento e desenvolvimento dos direitos da personalidade, tanto em sua dimensão física quanto psíquica, o que implica na mudança do paradigma da essência contratual, visto antes apenas e tão somente como instrumento a serviço da circulação de riquezas e obtenção de lucro, para um novo modelo contratual, mais humanista e transparente, onde o fator preponderante deve ser a dignidade da pessoa humana e não mais o lucro a qualquer custo, o que não significa dizer que este não seja permitido pelo ordenamento jurídico, vez que a ordem econômica de nosso País, está assentada na livre iniciativa e na valorização do trabalho humano.

Pretendeu também, ainda nesta linha de raciocínio, demonstrar a incansável ideia da busca da justiça contratual entre as partes envolvidas no negócio jurídico em epígrafe, de modo que o adimplemento contratual e, por consequência, a extinção do negócio jurídico, não se dê a custa do grave desequilíbrio financeiro de qualquer uma das partes, o que se traduz na essência do princípio da boa- 
fé objetiva, importante inovação, juntamente com a função social do contato, trazidas pelo Código Civil vigente, o qual exige que os contratos tenham equações econômicas razoavelmente equilibradas.

Desta forma, não se quis sustentar, como já dito alhures, que fosse pecado ou crime lucrar no contrato, especialmente nos contratos de prestação de serviços de saúde, dada a sua relevância social, vez que ninguém contrata por diletantismo ou altruísmo, pois é da essência do contrato a busca de um proveito econômico, principalmente numa sociedade capitalista como a de nosso País.

Todavia, esse proveito econômico agora tem o seu limite na exata definição do princípio da dignidade da pessoa humana, da eliminação da miséria, das injustiças sociais, o que releva a função social destes contratos, uma vez que eles não devem estar apenas a serviço dos contratantes, mas também da sociedade, e porque não dizer, através de uma eficaz regulação e fiscalização por parte dos entes estatais.

Assim, partindo destas premissas é que a interpretação dos contratos de serviços de prestação de serviços de saúde deve ser efetivada quando ocorrer um conflito entre os interesses antagônicos das partes contratantes, buscando sempre uma verdadeira justiça e equilíbrio contratuais, e mais do que isso, pois deve também o contrato buscar atingir a justiça social, impondo-se para tanto que o princípio da dignidade da pessoa humana seja considerado como núcleo básico e informador de todo ordenamento jurídico, como critério e parâmetro de valoração a orientar a interpretação e compreensão do sistema constitucional, que deve ser entendido em sua unicidade, e que privilegia determinados valores sociais, como o da dignidade da pessoa humana, nele erigido à condição de um valor essencial que the doa unidade de sentido.

Finalmente, como forma metafórica de retratar o ideário do presente estudo, o qual está aberto a discussões e posicionamentos contrários, vez que, segundo Orlando Carvalho: "Nenhum direito é definitivamente factum: é sempre alguma coisa in fieri", recorde-se o poema de Antonio Machado, abaixo colacionado, o qual retrata o caminho a ser percorrido na longa jornada para que um dia sejam efetivamente cumpridas as diretrizes sanitárias consagradas na Constituição Federal de 1988, as quais asseguram a toda pessoa o direito a uma prestação de serviços de saúde ampla e digna.

"Caminhante são teus rastos, o caminho, e nada mais; caminhante, não há caminho, faz-se o caminho ao andar. Ao andar faz-se o caminho, e ao olhar-se para trás vê-se a trilha, que jamais há de voltar a pisar. Caminhante, não há caminho, somente sulcos no mar." 


\section{REFERÊNCIAS}

BARROSO, Luís Roberto. Estudos de direito constitucional em homenagem a José Afonso da Silva. In: GRAU, Eros Roberto; CUNHA, Sérgio Sérvulo da (Coords.). Fundamentos teóricos e filosóficos do novo direito constitucional brasileiro. São Paulo: Malheiros, 2003.

BIERWAGEN, Mônica Yoshizato. Princípios e regras de interpretação dos contratos no novo código civil. 2. ed. São Paulo: Saraiva, 2003.

CRETELLA JÚNIOR, José. Direito romano moderno. 10. ed. Rio de Janeiro: Forense, 2001.

LÔBO NETTO, Condições gerais dos contratos e cláusulas abusivas. São Paulo: Saraiva, 1991.

LUDWIG, Marcos de Campos. O direito ao livre desenvolvimento da personalidade na Alemanha e possibilidades de sua aplicação no direito privado brasileiro. In: MARTINS-COSTA, Judith (Org.). A reconstrução do direito privado. São Paulo: Editora Revista dos Tribunais, 2002.

MARTINS, Flademir Jerônimo Belinati. Dignidade da pessoa humana: princípio constitucional fundamental. 1. ed (2003), 4. tir. Curitiba: Juruá, 2006.

MAURER, Béatrice. Notas sobre o respeito da dignidade da pessoa humana ou pequena fuga incompleta em torno de um tema central. In: SARLET, Ingo Wolfgang (Org.). Dimensões da dignidade da pessoa humana: ensaios de filosofia do direito e direito constitucional. Porto Alegre: Livraria do Advogado, 2005.

MORAES, Alexandre de. Direito constitucional. 7. ed. São Paulo: Atlas, 2000.

PEREIRA, Caio Mário da Silva. Instituições de direito civil. 11. ed. Rio de Janeiro: Forense, 2004. v. 3.

PIOVESAN, Flávia. Direitos humanos e o princípio da dignidade humana. In: PAULA, Alexandre Sturion de (Org.). Ensaios constitucionais de direitos fundamentais. Campinas: Servanda, 2006.

SANTOS, Fernando Ferreira dos. Princípio constitucional da dignidade da pessoa humana: uma análise do inciso III, do art. $1^{\underline{0}}$, da Constituição Federal de 1988. São Paulo: Celso Bastos, 1998.

SARLET, Ingo Wolfgang. A constituição concretizada: construindo pontes com o público e o privado. Porto Alegre: Livraria do Advogado, 2000. 
Dignidade da pessoa humana e diretos fundamentais. Porto Alegre: Livraria do Advogado, 2001.

VENOSA, Silvio de Salvo. Direito civil: parte geral. 3. ed. São Paulo: Atlas, 2003.

Artigo recebido em 14/08/10 e aprovado para publicação em 25/08/10 
